\title{
Association between Tumor Necrosis Factor- $\alpha$ (-238G/A and -308G/A) Gene Polymorphisms and Risk of Ischemic Stroke: A Meta-Analysis
}

\author{
Pradeep Kumar Shubham Misra Amit Kumar Awadh Kishor Pandit \\ Kamalesh Chakravarty Kameshwar Prasad \\ Department of Neurology, All India Institute of Medical Sciences, New Delhi, India
}

\section{Key Words}

Inflammatory gene · Polymorphisms · Tumor necrosis factor- $\alpha \cdot$ Cytokines $\cdot$ Ischemic stroke . Cerebral infarction · Meta-analysis

\begin{abstract}
Tumor necrosis factor- $\alpha$ (TNF- $\alpha$ ) is a proinflammatory pleiotropic cytokine which may contribute to the initiation and progression of ischemic stroke (IS). Thus far, numerous studies have been performed to examine the association between -238G/A (rs361525) and -308G/A ( $r$ 1800629) polymorphisms in the promoter regions of the TNF- $\alpha$ gene and susceptibility to IS, but results are still conflicting. The aim of this meta-analysis is to provide a relatively comprehensive account of the association between TNF- $\alpha-238 \mathrm{G} / \mathrm{A}$ and $-308 \mathrm{G} / \mathrm{A}$ gene polymorphisms and susceptibility to IS. A literature search for eligible candidate gene studies published before April 20, 2015, was conducted in the PubMed, Medline, EMBASE and Google Scholar databases. The following combinations of main keywords were used: ('Tumor Necrosis Factor-Alpha' or 'TNF- $\alpha$ ') and ('ischemic stroke' or 'cerebral infarction' or 'IS') and ('genetic polymorphism' or 'single nucleotide polymorphisms' or 'SNP'). Fixed- or random-effect models were used to estimate the pooled odds ratio (OR) and $95 \%$ confidence interval (CI). Meta-analysis was carried out by using RevMan 5.3 software. For TNF- $\alpha-238$ G/A gene polymorphism, 7 case-control studies with a total of 1,846 IS patients and 1,905 controls showed a significant association with susceptibility to IS under a dominant model (AA + GA vs. GG; OR, 1.40; 95\% CI, 1.11-1.76; $p$ value 0.004). For TNF- $\alpha-308 \mathrm{G} / \mathrm{A}$ gene polymorphism, 16 casecontrol studies with a total of 5,651 IS patients and 5,792 controls showed a significant protective association with susceptibility to IS under a dominant model (AA + GA vs. GG; OR, 0.78, $95 \%$ CI, 0.63-0.97; $p$ value 0.03 ). Our meta-analysis shows that TNF- $\alpha-238 \mathrm{G} / \mathrm{A}$ gene polymorphism is more likely to be associated with the risk of IS in Caucasian populations as compared
\end{abstract}


Kumar et al.: Association between Tumor Necrosis Factor- $\alpha$ (-238G/A and -308G/A)

Gene Polymorphisms and Risk of Ischemic Stroke: A Meta-Analysis

to Asian populations. However, TNF- $\alpha-308 \mathrm{G} / \mathrm{A}$ gene polymorphism is more likely to be protective against IS in Asian populations as compared to Caucasian populations. Further large, well-designed prospective epidemiological studies are needed to confirm these findings.

(C) 2016 S. Karger AG, Basel

\section{Introduction}

Stroke is one the leading causes of death in the world and a common cause of disability $[1,2]$. Ischemic stroke (IS) is a multifactorial, polygenic, complex disease resulting from the combination of vascular, environmental and genetic factors [3]. Inflammation and genetics are both prominent mechanisms in the pathogenesis of IS [4]. Candidate genes, stroke-susceptible alleles and their association with stroke pathogenesis have been intensely studied in the last few years [5-7]. Tumor necrosis factor- $\alpha$ (TNF- $\alpha$ ) is a pleiotropic proinflammatory cytokine which is mainly produced by macrophages, lymphocytes, natural killer cells and neurons [8]. The human TNF- $\alpha$ gene is located on chromosome $6 \mathrm{p} 21.3$, which consists of 4 small exons and encodes a protein of 233 amino acid residues.

TNF- $\alpha$ is known to play a significant role in the recruitment of leukocytes from the circulation, and therefore is a crucial determinant of inflammatory reaction in stroke $[9,10]$. TNF- $\alpha$ is also considered as a strongly deleterious cytokine in stroke and is involved in the expansion of brain infarcts. On the other hand, there is a suggestion that TNF- $\alpha$ may also play a neuroprotective role in stroke through downregulation of apoptosis $[11,12]$. Genetic screening of the TNF- $\alpha$ gene has revealed $-238 \mathrm{G} / \mathrm{A}$ and -308G/A polymorphic regions in the promoter region of TNF- $\alpha$, which has been associated with high TNF- $\alpha$ production. The increased level of TNF- $\alpha$ has severe effects on lipid metabolism, coagulation and endothelial function, which may contribute to the risk of IS $[13,14]$. However, a higher level of TNF- $\alpha$ might be expected to be associated with increased stroke risk, but some epidemiological evidence is of no significance.

Previous studies examining the association between TNF- $\alpha-238 \mathrm{G} / \mathrm{A}$ and $-308 \mathrm{G} / \mathrm{A}$ gene polymorphisms and IS showed inconclusive and contradictory results. Therefore, we performed a meta-analysis on all the published case-control studies to assess the association of TNF- $\alpha-238 \mathrm{G} / \mathrm{A}$ and $-308 \mathrm{G} / \mathrm{A}$ gene polymorphisms with the risk of IS.

\section{Materials and Methods}

\section{Identification of Relevant Studies}

A literature search for eligible candidate gene studies published before April 20, 2015, was conducted in the PubMed, Medline, EMBASE and Google Scholar databases. To avoid subjectivity in the choice of the time point, we fixed April 20, 2015, as the cutoff date for the inclusion of new studies. The following combinations of main keywords were used: ('tumor necrosis factor-alpha' or 'TNF- $\alpha$ ') and ('ischemic stroke' or 'cerebral infarction' or 'IS') and ('genetic polymorphism' or 'single nucleotide polymorphisms' or 'SNP'). The search was done without language restriction, but only included those studies that were conducted on human subjects. All references in eligible articles were extensively reviewed to identify additional published articles. Pooled odds ratios (OR) and 95\% confidence intervals (CI) were determined for TNF- $\alpha$ gene-disease association. The meta-analysis was carried out using RevMan 5.3 software.

\section{Inclusion and Exclusion Criteria}

To be included in the analysis, eligible studies had to meet the following criteria: (1) case-control studies on the association between the TNF- $\alpha-238 \mathrm{G} / \mathrm{A}$ or -308G/A gene polymorphisms and susceptibility to IS; (2) all patients in the candidate studies meeting the diagnostic criteria for IS, and (3) studies with sufficient available data to calculate ORs with corresponding 95\% CI. The major reasons for excluding studies were: 
Kumar et al.: Association between Tumor Necrosis Factor- $\alpha$ (-238G/A and -308G/A)

Gene Polymorphisms and Risk of Ischemic Stroke: A Meta-Analysis

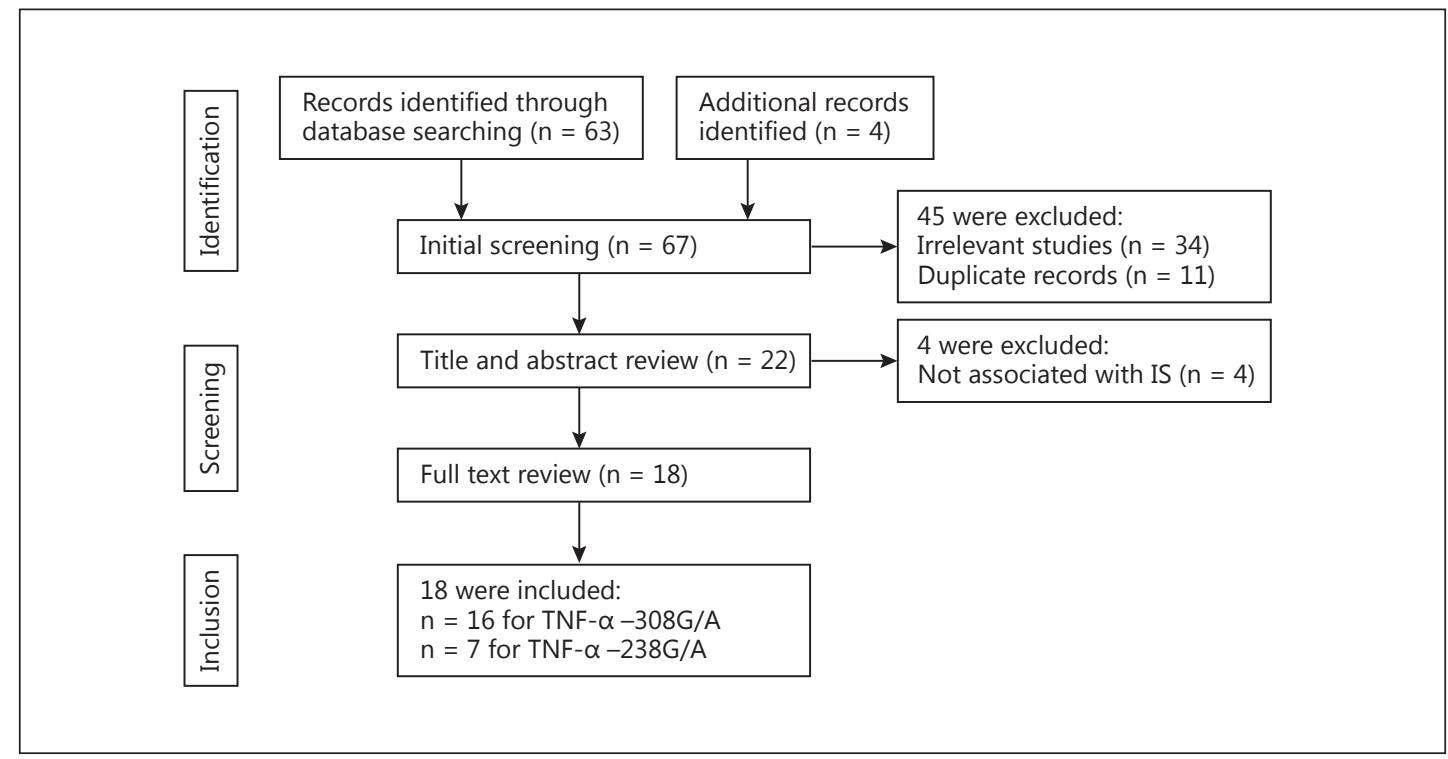

Fig. 1. Flow diagram of the selection of studies and specific reasons for exclusion from the present metaanalysis.

(1) not a case-control study; (2) duplicate publications with overlapping subjects from the same study, and (3) no available data reported. This meta-analysis was conducted according to the Preferred Reporting Items for Systematic Reviews and Meta-analysis (PRISMA) guideline [15]. No author was contacted regarding the missing information that was required for the meta-analysis to avoid the risk of retrieval bias [16].

\section{Data Extraction}

According to the PRISMA guidance, 2 investigators (P.K. and S.M.) independently checked each full-text report for eligibility and extracted the following data from eligible studies: surname of the first author, year of publication, country of origin, ethnicity, definition and number of cases and controls, age, sex ratio, genotyping method and genotype frequency, etc. Disagreements were solved by discussion between all authors until a consensus was reached.

\section{Quality Assessment}

We also evaluated the methodological quality of every study included in our analysis using a quality assessment scale developed for genetic association studies [17], which was modified by us to increase the relevance of our study. This scale took into account both traditional epidemiological considerations and genetic issues. The scores ranged from 0 (worst) to 16 (best). Details of the scale are presented in table 1. Two authors independently assessed the quality of the included studies. Discrepancies over quality scores were resolved by discussion with all authors and subsequent consensus.

\section{Statistical Analysis}

Genotype distributions in the controls were tested for agreement with the Hardy-Weinberg equilibrium (HWE) using the $\chi^{2}$ test. The association between the TNF- $\alpha$ genetic polymorphisms and susceptibility to IS was assessed by pooled ORs with their corresponding 95\% CI under three genetic models: dominant, recessive and co-dominant. Taking into consideration possible heterogeneity between studies, a statistical test for heterogeneity was first conducted using Cochran's Q statistics and $I^{2}$ metrics [18]. We considered the presence of significant heterogeneity at the $10 \%$ level of significance and values of $\mathrm{I}^{2}$ exceeding $50 \%$ as an indicator of significant heterogeneity. When no heterogeneity was found with $\mathrm{p}<0.10$ or $\mathrm{I}^{2}, 50 \%$, a fixedeffect model was used to estimate the pooled ORs and $95 \%$ CI. Otherwise, a random-effect model was applied. In addition to an overall comparison, stratified analyses based on ethnicity were used to investigate whether overall reported associations were present in subgroups. Begg's funnel plot was used to assess the potential for publication bias. 
Table 1. Scale for quality assessment

Criteria

Score

Representativeness of cases

Selected from any population disease registry or multiple center sites

Selected from any cardiology/neurology department

Not described

Source of controls

Population or neighbor based

Hospital based

Healthy volunteers with total description

Healthy volunteers without total description

Not described

Matching of controls

Age and sex match

Smoking, hypertensive, diabetic

Not matched

2

1

0

Ascertainment of IS

Adequate confirmation

Diagnosis of IS by patient medical record

Not described

Ascertainment of controls

Stroke-free status by using appropriate QVSFS or CT/MRI

Not described

1

0

Genotyping

Genotyping done under blinded conditions

Unblinded or not mentioned

1

0

Genotyping method

DNA sequencing/multiplex PCR

PCR-RFLP

Others

2

1

0

HWE

Allelic frequency in accordance with HWE

Not HWE but following statistics to adjust confounding

Not checked

Association assessment

Appropriate statistics and examining confounders and effect modifiers

Inappropriate statistics used

Total score

0

16

QVSFS = Questionnaire for Verifying Stroke-Free Status; PCR-RFLP = polymerase chain reactionrestriction fragment length polymorphism.

\section{Results}

A total of 67 published articles were identified using the prespecified search strategy. Figure 1 represents a flow chart of retrieved and excluded studies with their reasons for exclusion. Out of the 67 retrieved articles, 34 studies were excluded due to their irrelevance to our interest; 11 studies were excluded as they were in duplicate, and 4 studies were excluded as they did not show an association with IS. Finally, a total 18 of studies were included in this meta-analysis. 


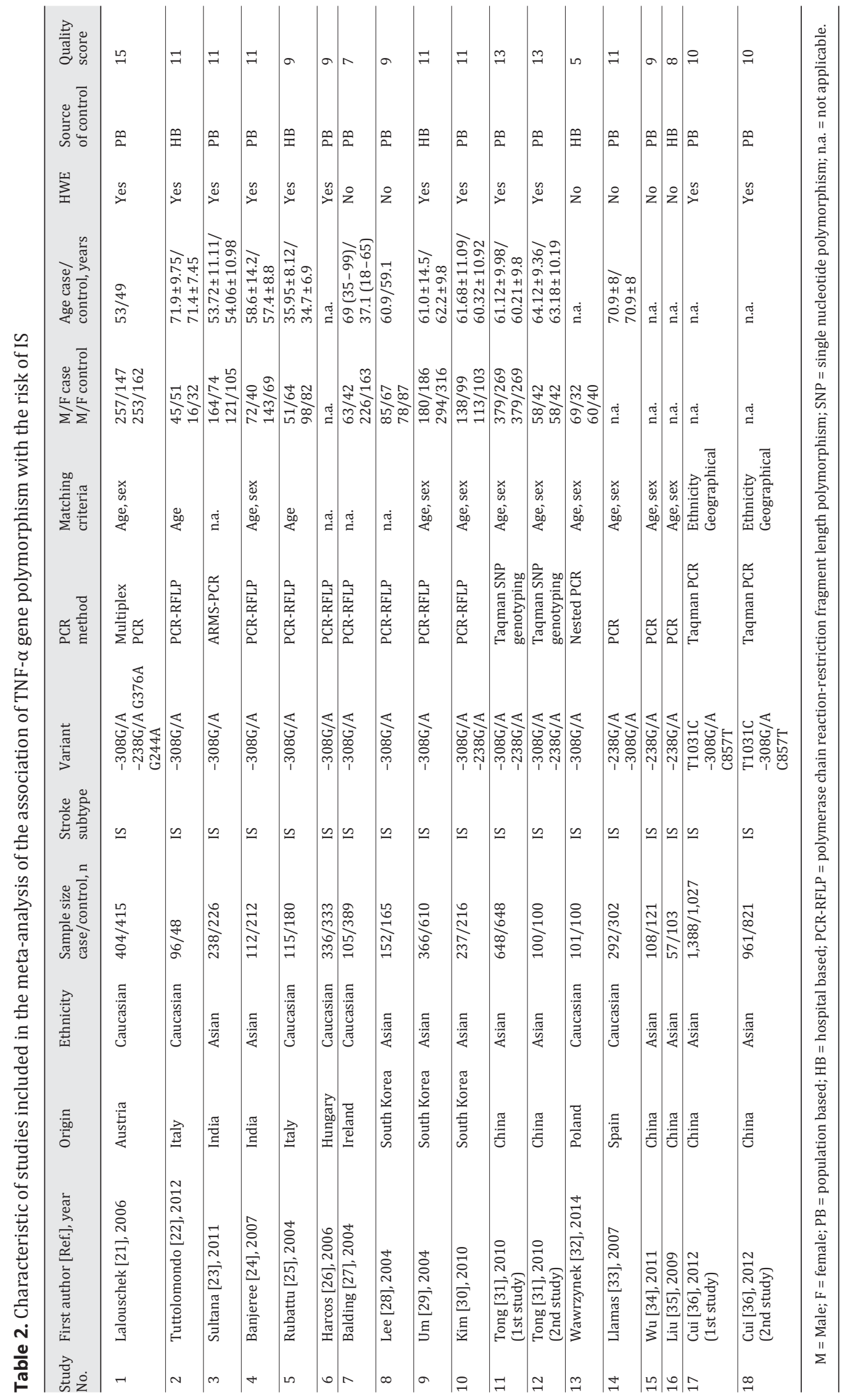


Kumar et al.: Association between Tumor Necrosis Factor- $\alpha$ (-238G/A and -308G/A)

Gene Polymorphisms and Risk of Ischemic Stroke: A Meta-Analysis

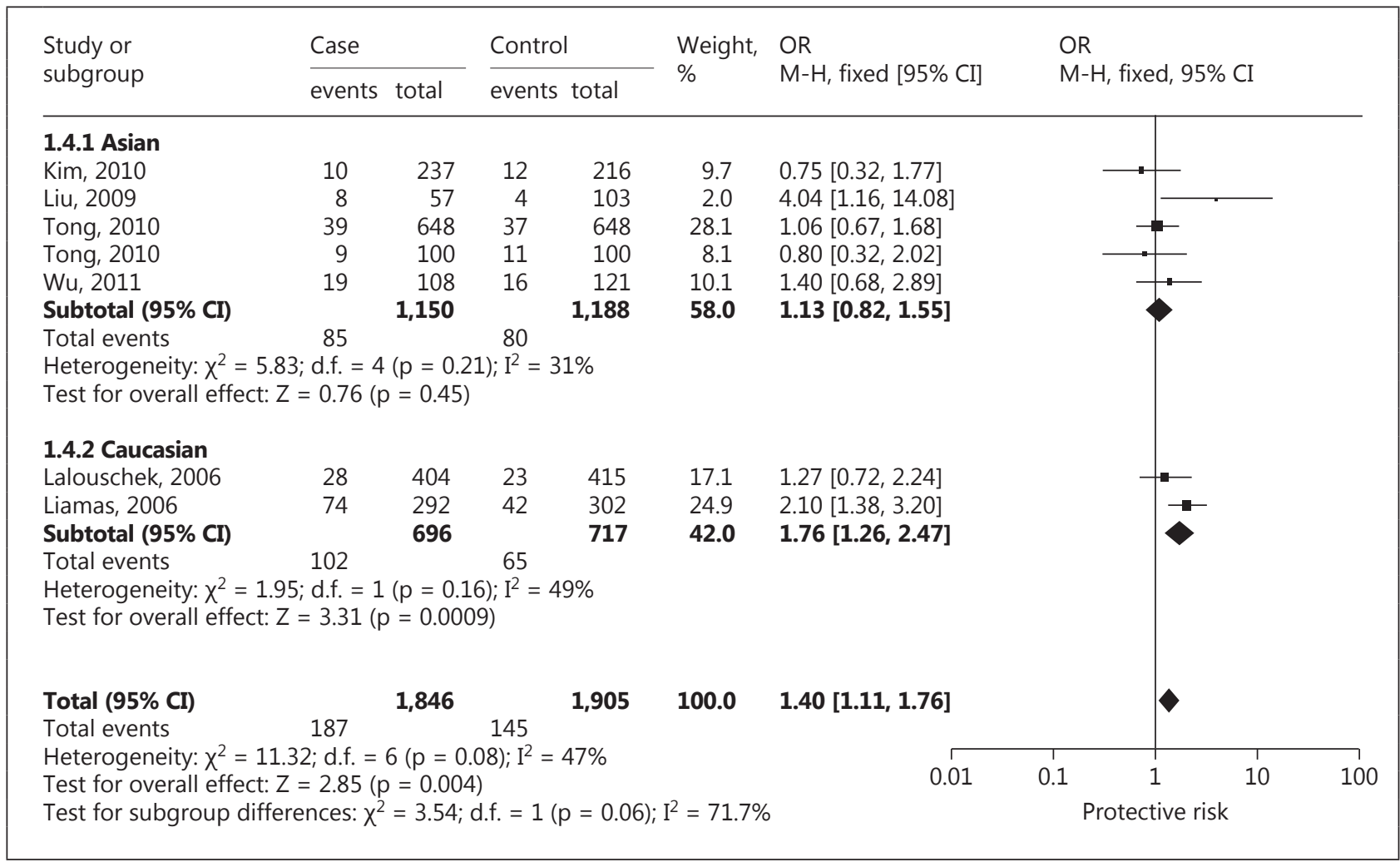

Fig. 2. Forest plot for association between TNF -238G/A polymorphism and IS risk under the dominant model.

Association of TNF- $\alpha-238$ G/A Gene Polymorphism with Susceptibility to IS

Seven case-control studies with a total of 1,846 IS patients and 1,905 controls also showed a significant association with susceptibility to IS under a dominant model (AA + GA vs. GG: OR, 1.40; 95\% CI, 1.11-1.76; $\mathrm{p}=0.004$ ). Studies were conducted in two major ethnic populations; 5 studies were in Asian and 2 studies in Caucasian populations. Four studies in this meta-analysis had controls in HWE. Six studies had population-based controls and 1 study had hospital-based controls. The quality scores of all included studies were moderately high. The characteristics and methodological quality of all included studies are summarized in table 2 .

Based on ethnicity stratification analysis, a significant association was observed in Caucasian studies (OR, 1.76; 95\% CI, 1.26-2.47; $\mathrm{p}=0.0009$ ), but a nonsignificant association was observed (OR, 1.13; 95\% CI, 0.82-1.55; $\mathrm{p}=0.45$ ) in Asian studies under a dominant model (fig. 2). Begg's funnel plots were used to assess the potential for publication bias of the included studies under a dominant model. The shapes of the funnel plots suggest a significant publication bias (fig. 3).

Association of TNF- $\alpha-308 G / A$ Gene Polymorphism with Susceptibility to IS

Sixteen case-control studies were included in this meta-analysis with a total of 5,651 IS patients and 5,792 controls. Studies were conducted in two major ethnic populations; 9 studies were conducted in Asian and 5 in Caucasian populations. The publication years of the included studies ranged from 2004 to 2014. Twelve studies in this meta-analysis had controls in HWE. Twelve studies had population-based controls and 4 studies had hospital-based 
Fig. 3. Begg's funnel plot for publication bias for TNF -238G/A gene polymorphism.
Kumar et al.: Association between Tumor Necrosis Factor- $\alpha$ (-238G/A and -308G/A) Gene Polymorphisms and Risk of Ischemic Stroke: A Meta-Analysis

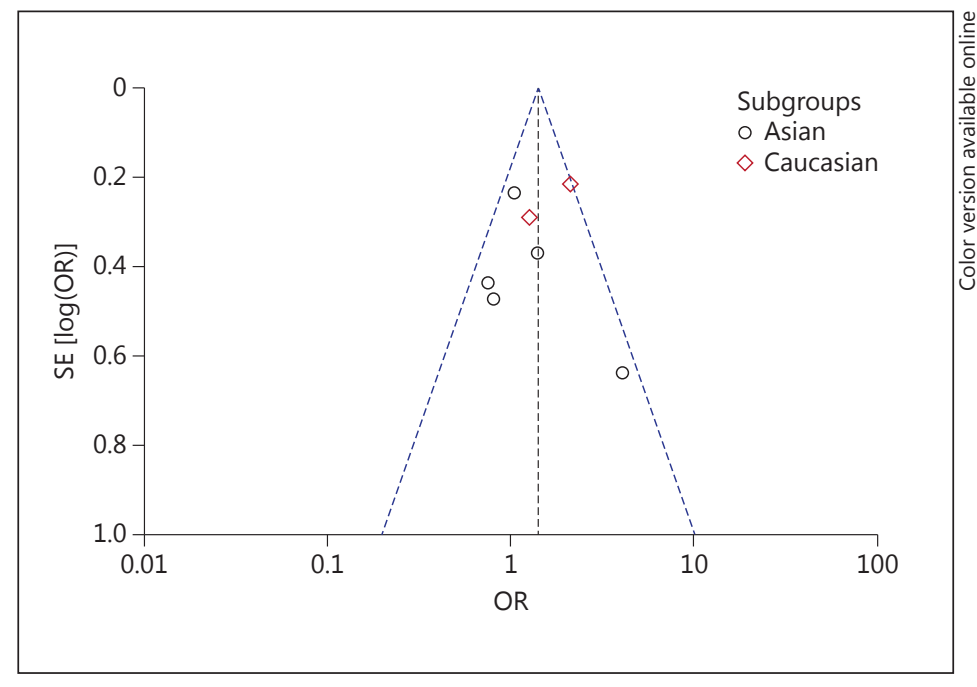

controls. The quality scores of all included studies were moderately high. The characteristics and methodological quality of all included studies are summarized in table 2.

A significant protective association with susceptibility to IS under dominant (AA + GA vs. GG: OR, 0.78; 95\% CI, 0.63-0.97; p = 0.03), recessive (AA vs. GG + GA: OR, 0.75; 95\% CI, 0.511.11; $\mathrm{p}=0.15$ ) and co-dominant models (GA vs. AA + GG: OR, 0.79; 95\% CI, 0.64-0.97; $\mathrm{p}=$ 0.03 ) was observed. Based on ethnicity stratification analysis, a more significant protective association with IS was observed under dominant (AA + GA vs. GG: OR, 0.67; 95\% CI, 0.520.87; $p=0.003$ ), recessive (AA vs. GG + GA: OR, 0.61; 95\% CI, 0.34-1.09; $p=0.10$ ) and co-dominant models (GA vs. AA + GG: OR, 0.69; 95\% CI, 0.53-0.89; $\mathrm{p}=0.004$ ) in Asian studies as compared to Caucasian studies under dominant (AA + GA vs. GG: OR, 0.94; 95\% CI, 0.671.32; $\mathrm{p}=0.73$ ), recessive (AA vs. GG + GA: OR, 0.89; 95\% CI, 0.53-1.49; $\mathrm{p}=0.66$ ) and co-dominant models (GA vs. AA + GG: OR, 0.93; 95\% CI, 0.67-1.30; $p=0.68$; fig. 4). Begg's funnel plots were used to assess the potential for publication bias of the included studies under a dominant model. The shapes of the funnel plots suggest a significant publication bias (fig. 5).

\section{Discussion}

According to the results of the present meta-analysis, TNF- $\alpha-238 \mathrm{G} / \mathrm{A}$ polymorphism increases the risk of IS, but TNF- $\alpha-308 \mathrm{G} / \mathrm{A}$ polymorphism appears to protect against IS. However, a recessive model of Caucasian studies involving 1,449 cases and 1,767 controls suggests that the $-308 \mathrm{G} / \mathrm{A}$ variant might be a risk factor for IS. In the subgroup analysis by ethnicity, a more significant increased risk of IS was found in Caucasian studies as compared to Asian studies for -238G/A TNF- $\alpha$ gene polymorphism. Based on ethnicity stratification, varying results were obtained, which may be due to different genetic regions and environments having different religions, languages and customs. The differences in the genetic backgrounds of smoking, alcohol intake, diet, infection, congenital or acquired heart disease, and metabolic and hematological disorders may represent risk factors for IS. The protective nature of TNF- $\alpha-308$ G/A gene polymorphisms may be due to the modest effect played by this molecular gene variant along with the notion of a multifactorial and polygenic etiology of IS, where each genetic determinant plays a small contributory role. 
Kumar et al.: Association between Tumor Necrosis Factor- $\alpha$ (-238G/A and -308G/A)

\section{a Dominant model [-308G/A]}

Study or

subgroup

Case

\section{Control} events total
Weight,

OR M-H random $[95 \% \mathrm{CI}]$
OR M-H, random, 95\% CI

\subsubsection{Asian}

Banerjee, 2007

Cui, 2012

Cui, 2012

Kim, 2010

Lee, 2004

Sultana, 2011

Tong, 2010

Tong, 2010

Um, 2004

Subtotal $(95 \% \mathrm{CI})$

Total events

(1)

Heterogeneity: $\tau^{2}=0.09 ; x^{2}=21.68 ;$ d.f. $=8(p=0.006) ; I^{2}=63 \%$

Test for overall effect: $Z=3.01(p=0.003)$

\subsubsection{Caucasian}

Balding, 2004

Harcos, 2006

Lalouschek, 2006

Liamas, 2006

Rubattu, 2004

Tuttolomondo, 2012

Wawrzynek, 2014

Subtotal $(95 \% \mathrm{CI})$

Total events

$\begin{array}{rrrrrl}17 & 112 & 31 & 212 & 5.3 & 1.04[0.55,1.98] \\ 151 & 1,388 & 141 & 1,027 & 8.8 & 0.77[0.60,0.98] \\ 93 & 961 & 111 & 821 & 8.4 & 0.69[0.51,0.92] \\ 17 & 237 & 26 & 216 & 5.3 & 0.56[0.30,1.07] \\ 16 & 152 & 8 & 165 & 3.8 & 2.31[0.96,5.56] \\ 221 & 238 & 214 & 226 & 4.5 & 0.73[0.34,1.56] \\ 51 & 648 & 96 & 648 & 7.8 & 0.49[0.34,0.70] \\ 8 & 100 & 30 & 100 & 4.0 & 0.20[0.09,0.47] \\ 41 & 366 & 101 & 610 & 7.5 & 0.64[0.43,0.94] \\ & \mathbf{4 , 2 0 2} & & \mathbf{4 , 0 2 5} & \mathbf{5 5 . 5} & \mathbf{0 . 6 7}[\mathbf{0 . 5 2}, \mathbf{0 . 8 7}] \\ 615 & & 758 & & & \end{array}$

$1.04[0.55,1.98]$

$0.69[0.51,0.92]$

$0.56[0.30,1.07]$

$2.31[0.96,5.56]$

$0.73[0.34,1.56]$

$0.49[0.34,0.70]$

$0.20[0.09,0.47]$

$0.67[0.52,0.87]$

8]

Heterogeneity: $\tau^{2}=0.14 ; x^{2}=21.04 ;$ d.f. $=6(p=0.002) ; I^{2}=71 \%$

Test for overall effect: $Z=0.35(p=0.73)$

Total $(95 \% \mathrm{CI})$

Total events

Heterogeneity: $\operatorname{tau}^{2}=0.13 ; \chi^{2}=52.87 ;$ d.f. $=15(p=0.00001) ; I^{2}=72 \%$
Test for overall effect: $Z=2.20(p=0.03)$

Test for subgroup differences: $\chi^{2}=2.42 ;$ d.f. $=1(p=0.12) ; I^{2}=58.7 \%$
$1.16[0.75,1.80]$

$0.62[0.44,0.88]$

$1.28[0.94,1.74]$

$0.76[0.50,1.17]$

$2.00[1.13,3.56]$

$0.42[0.18,1.00]$

$0.84[0.39,1.84]$

$0.94[0.67,1.32]$

479

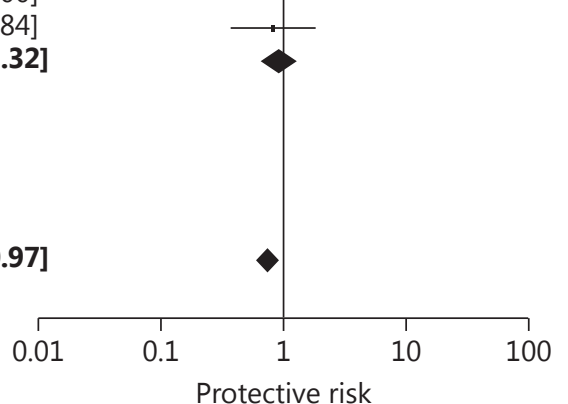

Fig. 4. Forest plot for association between TNF -308 G/A polymorphism and IS risk under the dominant (a), recessive (b) and co-dominant (c) models.

(For figure $4 b$, c see next pages.)

We included all the recently published studies to extract more evidence and draw a precise conclusion for the association between TNF- $\alpha$ gene polymorphisms and the risk of IS. Our findings are in accordance with the previously published meta-analyses by Gu et al. [18] for -238G/A polymorphism and Gu et al. [19] and Pereira et al. [20] for -308G/A polymorphism. Various genome-wide association studies (GWAS) for stroke have been published [36-41], but most of these study populations were of Caucasian origin, and they did not detect the association of TNF- $\alpha-238 \mathrm{G} / \mathrm{A}$ and -308G/A polymorphisms in the TNF- $\alpha$ gene with stroke. Indeed, similar negative results were obtained from the European populations reported by Freilinger et al. [42]. Recently, due to the small sample size in stage 1 of GWAS screening (131 cases and 135 controls), the GWAS performed in the Japanese population [39] did not have a sufficient power to observe a positive association.

The present meta-analysis must be interpreted with caution because of certain limitations. First, the studies included in this meta-analysis varied in ethnicity, age and environmental factors. Second, the use of different methodologies for the genotyping method, 


\section{b Recessive model [-308G/A]}

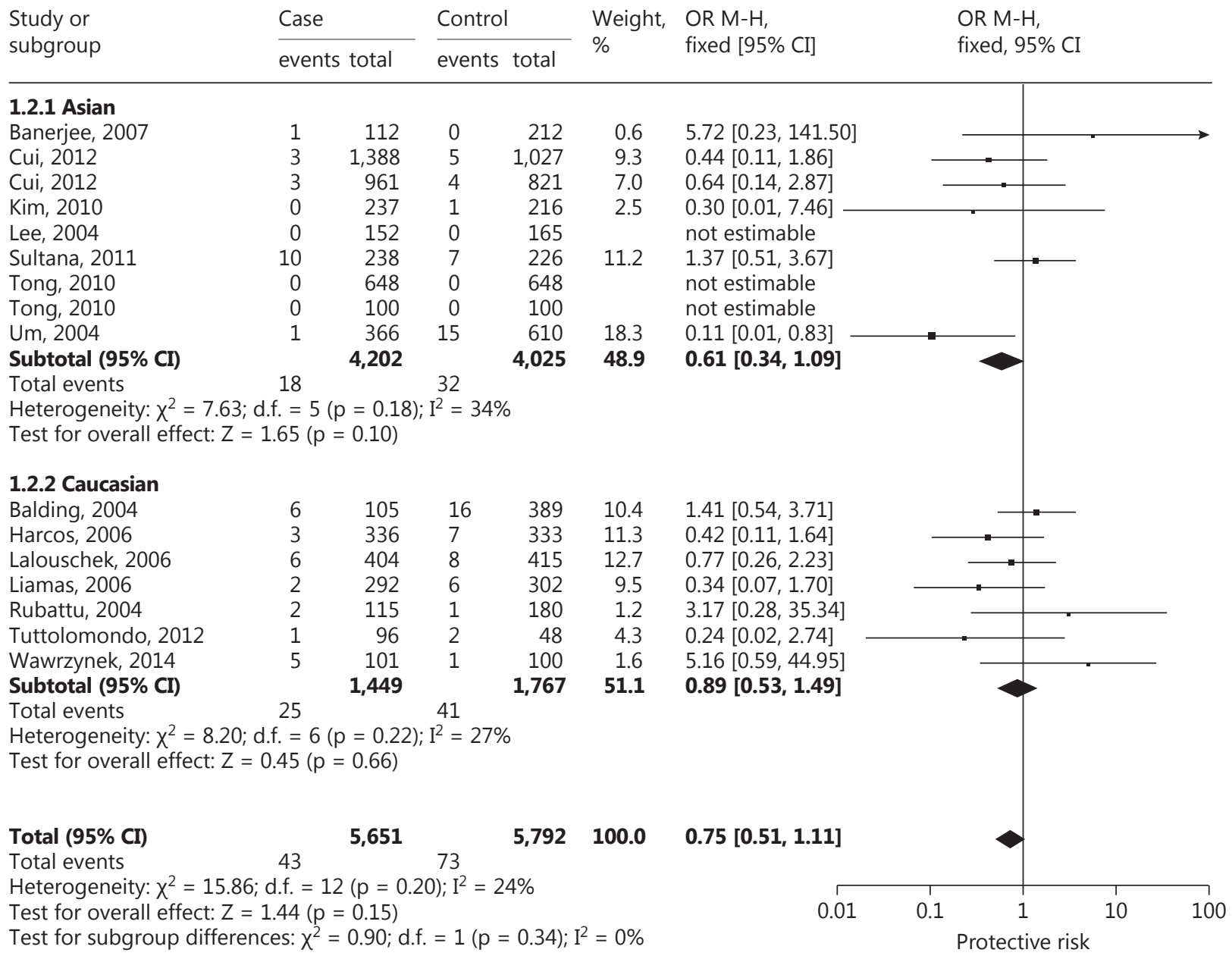

selection of controls and matching criteria may have led to heterogeneity. Third, not all other variants $(-857 \mathrm{C} / \mathrm{T},-863 \mathrm{C} / \mathrm{A},-1031 \mathrm{~T} / \mathrm{C})$ located in the human TNF- $\alpha$ promoter gene were assessed in this study. Complete sequencing will be necessary for systematic identification of potentially causative mutations in the TNF- $\alpha$ whole-gene function region.

In addition, genetic tests are needed to assess the clinical utility of drugs and doses routinely used to treat patients with stroke or at risk of stroke. The protective nature of TNF- $\alpha$ gene polymorphism may be beneficial to patients based on genotyping and functional assay of the whole TNF- $\alpha$ promoter gene. Finding a link between inflammatory genetic markers and cerebrovascular events will certainly require a careful study of well-characterized and phenotypically homogeneous subjects as well as meticulous analyses of gene-gene and gene-environment interactions by prospective studies. The prospective design will be important not only to avoid survival bias, but also to address issues underexplored thus far, such as age at stroke. Also, additional approaches such as haplotypic analysis with markers in the vicinity of TNF- $\alpha$ may provide more informative and useful data for the study of the genetic etiology of cerebrovascular diseases than single-genotype-based data. 
Kumar et al.: Association between Tumor Necrosis Factor- $\alpha$ (-238G/A and -308G/A)

\section{c Co-dominant model $[-308 \mathrm{G} / \mathrm{A}]$}

Study or

subgroup
Case

events total
Control events total
Weight, OR M-H, random [95\% CI]
OR M-H,

random, 95\% CI

\subsubsection{Asian}

Banerjee, 2007

Cui, 2012

Cui, 2012

Kim, 2010

Lee, 2004

Sultana, 2011

Tong, 2010

Tong, 2010

Um, 2004

Subtotal $(95 \% \mathrm{CI})$

$\begin{array}{rr}16 & 112 \\ 148 & 1,388 \\ 90 & 961 \\ 17 & 237 \\ 16 & 152 \\ 211 & 238 \\ 51 & 648 \\ 8 & 100 \\ 40 & 366 \\ & \mathbf{4 , 2 0 2}\end{array}$

$\begin{array}{rr}31 & 212 \\ 136 & 1,027\end{array}$

$107 \quad 821$

$25 \quad 216$

$8 \quad 165$

$207 \quad 226$

$96 \quad 648$

30100

610
4,025

\section{2}

9.0

8.5

5.3

3.7

5.5

7.9

3.9

3.9
7.5
56.5

Total events 597

\section{6}

56.5

$0.97[0.51,1.87]$

$0.78[0.61,1.00]$

$0.69[0.51,0.93]$

$0.59[0.31,1.13]$

$2.31[0.96,5.56]$

$0.72[0.39,1.33]$

$0.49[0.34,0.70]$

$0.20[0.09,0.47]$

$0.75[0.50,1.12]$

$0.69[0.53,0.89]$

Heterogeneity: $\tau^{2}=0.08 ; x^{2}=21.30 ;$ d.f. $=8(p=0.006) ; I^{2}=62 \%$

Test for overall effect: $Z=2.88(p=0.004)$

\subsubsection{Caucasian}

Balding, 2004

Harcos, 2006

Lalouschek, 2006

Liamas, 2006

Rubattu, 2004

Tuttolomondo, 2012

Wawrzynek, 2014

Subtotal $(95 \% \mathrm{CI})$

Total events

$\begin{array}{rr}40 & 105 \\ 71 & 336 \\ 116 & 404 \\ 42 & 292 \\ 29 & 115 \\ 12 & 96 \\ 9 & 101 \\ & \mathbf{1 4 4 9}\end{array}$

$$
\begin{array}{rr}
140 & 389 \\
97 & 333
\end{array}
$$

$97 \quad 333$

$\begin{array}{ll}51 & 415 \\ 27 & 180\end{array}$

$27 \quad 180$

$11 \quad 48$

$15 \quad 100$

1,767

$7.1 \quad 1.09[0.70,1.71]$

$8.0 \quad 0.65[0.46,0.93]$

$8.4 \quad 1.32[0.97,1.81]$

$7.10 .83[0.53,1.29]$

$5.7 \quad 1.91[1.06,3.44]$

3.6

$0.48[0.19,1.19]$

$0.55[0.23,1.33]$

438

3.7
43.5

$0.93[0.67,1.30]$

Heterogeneity: $\tau^{2}=0.12 ; \chi^{2}=18.38 ;$ d.f. $=6(p=0.005) ; I^{2}=67 \%$

Test for overall effect: $Z=0.41(p=0.68)$

Total $(95 \% \mathrm{CI})$

Total events

5,651

916

Heterogeneity: $\tau^{2}=0.11 ; \chi^{2}=48.74 ;$ d.f. $=15(p<0.0001) ; I^{2}=69 \%$

Test for overall effect: $Z=2.22(p=0.03)$

Test for subgroup differences: $\chi^{2}=2.11 ;$ d.f. $=1(p=0.15) ; I^{2}=52.6 \%$
$0.79[0.64,0.97]$

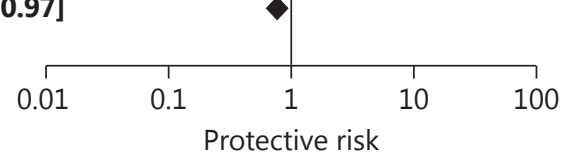

Fig. 5. Begg's funnel plot for publication bias for TNF -308G/A gene polymorphism.

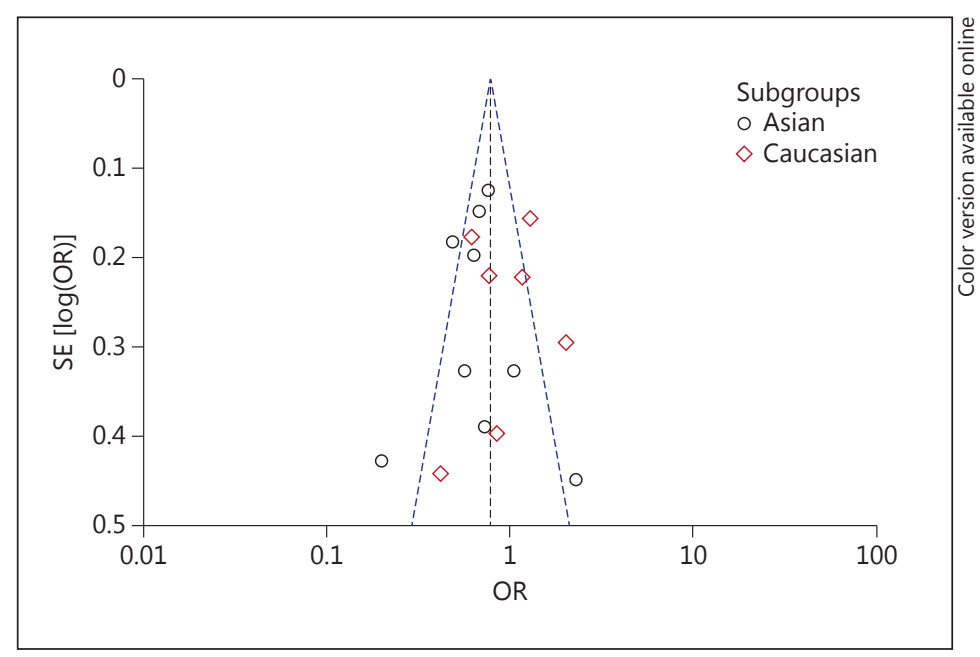


Kumar et al.: Association between Tumor Necrosis Factor- $\alpha$ (-238G/A and -308G/A)

Gene Polymorphisms and Risk of Ischemic Stroke: A Meta-Analysis

In summary, the present meta-analysis shows a protective effect of TNF- $\alpha-308 \mathrm{G} / \mathrm{A}$ gene polymorphism on IS risk, but a significant association was observed between TNF- $\alpha-238 \mathrm{G} / \mathrm{A}$ gene polymorphism and the risk of IS. However, TNF- $\alpha-308 \mathrm{G} / \mathrm{A}$ gene polymorphism might be associated with IS as observed in the recessive model of the Caucasian population. More credible evidence is required to draw solid conclusions on the association between TNF- $\alpha$ $-238 \mathrm{G} / \mathrm{A}$ and $-308 \mathrm{G} / \mathrm{A}$ gene polymorphisms and the risk of IS.

\section{Conclusion}

Our meta-analysis shows that TNF- $\alpha-238 \mathrm{G} / \mathrm{A}$ gene polymorphism is more likely to be associated with the risk of IS in Caucasian populations than in Asian populations. However, TNF- $\alpha-308 \mathrm{G} / \mathrm{A}$ gene polymorphism is more likely to be protective against IS in Asian populations as compared to Caucasian populations. Further large, prospective, epidemiological studies are needed to confirm these findings.

\section{Disclosure Statement}

The authors declare that there is no potential conflict of interest relevant to this article.

\section{References}

1 Feigin VL, Lawes CMM, Bennett DA, Barker-Collo SL, Parag V: Worldwide stroke incidence and early case fatality reported in 56 population-based studies: a systematic review. Lancet Neurol 2009;8:355-369.

2 Bevan S, Markus HS: Genetics of common polygenic ischaemic stroke: current understanding and future challenges. Stroke Res Treat 2011;2011:179061.

3 Kim SK, Kang SW, Kim DH, Yun DH, Chung J-H, Ban JY: Matrix metalloproteinase-3 gene polymorphisms are associated with ischemic stroke. J Interferon Cytokine Res Off J Int Soc Interferon Cytokine Res 2012;32: 81-86.

4 Jin R, Yang G, Li G: Inflammatory mechanisms in ischemic stroke: role of inflammatory cells. J Leukoc Biol 2010;87:779-789.

5 Carr FJ, McBride MW, Carswell HVO, Graham D, Strahorn P, Clark JS, et al: Genetic aspects of stroke: human and experimental studies. J Cereb Blood Flow Metab Off J Int Soc Cereb Blood Flow Metab 2002;22:767-773.

6 Hansson GK: Inflammation, atherosclerosis, and coronary artery disease. N Engl J Med 2005;352:1685-1695.

7 Bazzoni F, Beutler B: The tumor necrosis factor ligand and receptor families. N Engl J Med 1996;334:17171725.

8 Terry CM, Clikeman JA, Hoidal JR, Callahan KS: TNF-alpha and IL-1alpha induce heme oxygenase-1 via protein kinase C, $\mathrm{Ca}^{2+}$, and phospholipase $\mathrm{A}_{2}$ in endothelial cells. Am J Physiol 1999;276:H1493-H1501.

9 Mark KS, Trickler WJ, Miller DW: Tumor necrosis factor-alpha induces cyclooxygenase-2 expression and prostaglandin release in brain microvessel endothelial cells. J Pharmacol Exp Ther 2001;297:1051-1058.

10 Hallenbeck JM: The many faces of tumor necrosis factor in stroke. Nat Med 2002;8:1363-1368.

11 Kitagawa K, Matsumoto M, Mabuchi T, Yagita Y, Ohtsuki T, Hori M, et al: Deficiency of intercellular adhesion molecule 1 attenuates microcirculatory disturbance and infarction size in focal cerebral ischemia. J Cereb Blood Flow Metab Off J Int Soc Cereb Blood Flow Metab 1998;18:1336-1345.

12 Barone FC, Arvin B, White RF, Miller A, Webb CL, Willette RN, et al: Tumor necrosis factor-alpha. A mediator of focal ischemic brain injury. Stroke J Cereb Circ 1997;28:1233-1244.

13 Mekinian A, Tamouza R, Pavy S, Gestermann N, Ittah M, Mariette X, et al: Functional study of TNF- $\alpha$ promoter polymorphisms: literature review and meta-analysis. Eur Cytokine Netw 2011;22:88-102.

14 Moher D, Liberati A, Tetzlaff J, Altman DG; PRISMA Group: Preferred reporting items for systematic reviews and meta-analyses: the PRISMA statement. PLoS Med 2009;6:e1000097.

15 Bauer T, Bouman HJ, van Werkum JW, Ford NF, ten Berg JM, Taubert D: Impact of CYP2C19 variant genotypes on clinical efficacy of antiplatelet treatment with clopidogrel: systematic review and meta-analysis. BMJ 2011; 343:d4588.

16 Attia J, Thakkinstian A, D’Este C: Meta-analyses of molecular association studies: methodologic lessons for genetic epidemiology. J Clin Epidemiol 2003;56:297-303. 
Kumar et al.: Association between Tumor Necrosis Factor- $\alpha$ (-238G/A and -308G/A)

Gene Polymorphisms and Risk of Ischemic Stroke: A Meta-Analysis

17 Higgins JPT, Thompson SG, Deeks JJ, Altman DG: Measuring inconsistency in meta-analyses. BMJ 2003;327: 557-560.

$18 \mathrm{Gu}$ L, Su L, Wu G, Chen Q, Yan Y, Xie J, et al: Association between TNF- $\delta$ 238G/A polymorphisms and the risk of ischemic stroke. Int J Neurosci 2013;123:1-6.

19 Gu L, Wu G, Long J, Su L, Yan Y, Chen Q, et al: The role of TNF- $\alpha$ 308G>A polymorphism in the risk for ischemic stroke. Am J Med Sci 2013;345:227-233.

20 Pereira TV, Rudnicki M, Franco RF, Pereira AC, Krieger JE: Effect of the G-308A polymorphism of the tumor necrosis factor alpha gene on the risk of ischemic heart disease and ischemic stroke: a meta-analysis. Am Heart J 2007;153:821-830.

21 Lalouschek W, Schillinger M, Hsieh K, Endler G, Greisenegger S, Marculescu R, et al: Polymorphisms of the inflammatory system and risk of ischemic cerebrovascular events. Clin Chem Lab Med 2006;44:918-23.

22 Tuttolomondo A, Di Raimondo D, Forte GI, Casuccio A, Vaccarino L, Scola L, et al: Single nucleotide polymorphisms (SNPs) of pro-inflammatory/anti-inflammatory and thrombotic/fibrinolytic genes in patients with acute ischemic stroke in relation to TOAST subtype. Cytokine 2012;58:398-405.

23 Sultana S, Kolla VK, Jeedigunta Y, Penagaluru PK, Joshi S, Rani PU, et al: Tumour necrosis factor alpha and interleukin 10 gene polymorphisms and the risk of ischemic stroke in south Indian population. J Genet 2011; 90:361-364.

24 Banerjee I, Gupta V, Ahmed T, Faizaan M, Agarwal P, Ganesh S: Inflammatory system gene polymorphism and the risk of stroke: a case-control study in an Indian population. Brain Res Bull 2008;75:158-65.

25 Rubattu S, Speranza R, Ferrari M, Evangelista A, Beccia M, Stanzione R, et al: A role of TNF-alpha gene variant on juvenile ischemic stroke: a case-control study. Eur J Neurol 2005;12:989-993.

26 Harcos P, Laki J, Kiszel P, Széplaki Z, Szolnoki Z, Kovács M, et al: Decreased frequency of the TNF2 allele of TNF-alpha -308 promoter polymorphism is associated with lacunar infarction. Cytokine 2006;33:100-105.

27 Balding J, Livingstone WJ, Pittock SJ, Mynett-Johnson L, Ahern T, Hodgson A, et al: The IL-6 G-174C polymorphism may be associated with ischaemic stroke in patients without a history of hypertension. Ir J Med Sci 2004;173:200-203.

28 Lee B-C, Ahn S-Y, Doo H-K, Yim S-V, Lee H-J, Jin S-Y, et al: Susceptibility for ischemic stroke in Korean population is associated with polymorphisms of the interleukin-1 receptor antagonist and tumor necrosis factoralpha genes, but not the interleukin-1beta gene. Neurosci Lett 2004;357:33-6.

29 Um J-Y, Kim H-M: Tumor necrosis factor alpha gene polymorphism is associated with cerebral infarction. Brain Res Mol Brain Res 2004;122:99-102.

30 Kim OJ, Lee JH, Choi JK, Oh SH, Hong SH, Oh D, et al: Association between tumor necrosis factor-alpha (-308G $\rightarrow$ A and $-238 \mathrm{G} \rightarrow \mathrm{A}$ ) polymorphisms and homocysteine levels in patients with ischemic strokes and silent brain infarctions. Cerebrovasc Dis 2010;30:483-90.

31 Tong Y, Geng Y, Xu J, Wang Z, Zhang Y, Lin L, et al: The role of functional polymorphisms of the TNF-alpha gene promoter in the risk of ischemic stroke in Chinese Han and Uyghur populations: two case-control studies. Clin Chim Acta 2010; 411:1291-5.

32 Wawrzynek A, Dobiała J, Wender M, Kozubski W, Michałowska-Wender G: TNF $\alpha$ gene G-308A polymorphism and the risk of ischemic stroke. Neurol Neurochir Pol 2014;48:387-390.

33 Llamas Sillero P, Fernández de Velasco Casarrubios J, García-Raso A, Meseguer Gancedo E, Santos Montero AB, Tomás Martínez JF: Polymorphism -238 G/A of tumor necrosis factor alpha gene promoter is a genetic risk factor for ischemic cerebrovascular disease. J Mol Neurosci 2007; 32:108-110.

34 Wu K, Li G-j, Wang Z: Association study of TNF $\alpha-238$ G/A polymorphisnis in senior Han patients with cerebral infarction in Haina. Chin J Geriatr Heart Brain Vessel Dis 2011;13:1011-1012.

35 Liu Z-W, et al: Study on TNF-a 238G/A polymorphisms in patients with cerebral infarction. Anat Res 2009;31: 259-262.

36 Cui G, Wang H, Li R, Zhang L, Li Z, Wang Y, et al: Polymorphism of tumor necrosis factor alpha (TNF-alpha) gene promoter, circulating TNF-alpha level, and cardiovascular risk factor for ischemic stroke. J Neuroinflammation 2012;9:235.

37 Kubo M, Hata J, Ninomiya T, Matsuda K, Yonemoto K, Nakano T, et al: A nonsynonymous SNP in PRKCH (protein kinase C eta) increases the risk of cerebral infarction. Nat Genet 2007;39:212-217.

38 Ikram MA, Seshadri S, Bis JC, Fornage M, DeStefano AL, Aulchenko YS, et al: Genomewide association studies of stroke. N Engl J Med 2009;360:1718-1728.

39 Yamada Y, Fuku N, Tanaka M, Aoyagi Y, Sawabe M, Metoki N, et al: Identification of CELSR1 as a susceptibility gene for ischemic stroke in Japanese individuals by a genome-wide association study. Atherosclerosis 2009; 207:144-149.

40 International Stroke Genetics Consortium (ISGC), Wellcome Trust Case Control Consortium 2 (WTCCC2), Bellenguez C, Bevan S, Gschwendtner A, Spencer CCA, et al: Genome-wide association study identifies a variant in HDAC9 associated with large vessel ischemic stroke. Nat Genet 2012;44:328-333.

41 Kilarski LL, Achterberg S, Devan WJ, Traylor M, Malik R, Lindgren A, et al: Meta-analysis in more than 17,900 cases of ischemic stroke reveals a novel association at 12q24.12. Neurology 2014;83:678-685.

42 Freilinger T, Bevan S, Ripke S, Gschwendtner A, Lichtner P, Müller-Myhsok B, et al: Genetic variation in the lymphotoxin-alpha pathway and the risk of ischemic stroke in European populations. Stroke J Cereb Circ 2009;40:970-972. 